tirely from the stop-cock B. Hydrochloric acid rarely gets beyond the condenser, and the downward pitch of the drying tube $F \mathrm{G}$ hastens the passage of the carbonic acid gas. The whole apparatus occupies less than two square feet of desk room.

UNIVERSITY OF ILLINOIS, AUGUST 25, I 893 .

\title{
THE SPECIFIC GRAVITIES OF SOME GEM STONES.'
}

BY A. L,YVERSIDGE, M.A., F.R.S., PKOFESSOR OF ChEMISTRY, UNIVERSITY OF SYDXEY.

THE following tables contain the specific gravities of some gem stones which were all in the cut and polished condition except in the cases specified. As the specimens were sufficiently free from flaws and mechanical impurities to be cut and polished for jewelry, the specific gravities can be taken as those of typically pure minerals and the results should be more satisfactory than those obtained from ordinary cabinet specimens, unless it can be shown that the specific gravity is altered by the pressure and other treatment they have received during the process of cutting and polishing.

The specific gravities were taken with special care on an Oertling's best chemical balance by direct weighing, i. e., by suspending the specimen in a very small and light metal stirrup in distilled water. A specific gravity bottle was found, as is well known, to give less accurate results.

The temperature at the time of the determination is given in all cases and the results are corrected to $4^{\circ} \mathrm{C}$. according to Rossetti's determinations of the density of water.

In the last column are given the extremes of specific grarity as given by $F$. W. Clarke in his Constants of Nature.

The numbers refer to those in my catalogue of specimens and added in case of future reference.

1 Read before the Worid's Congress of Chemists. August 23. 1893 . 


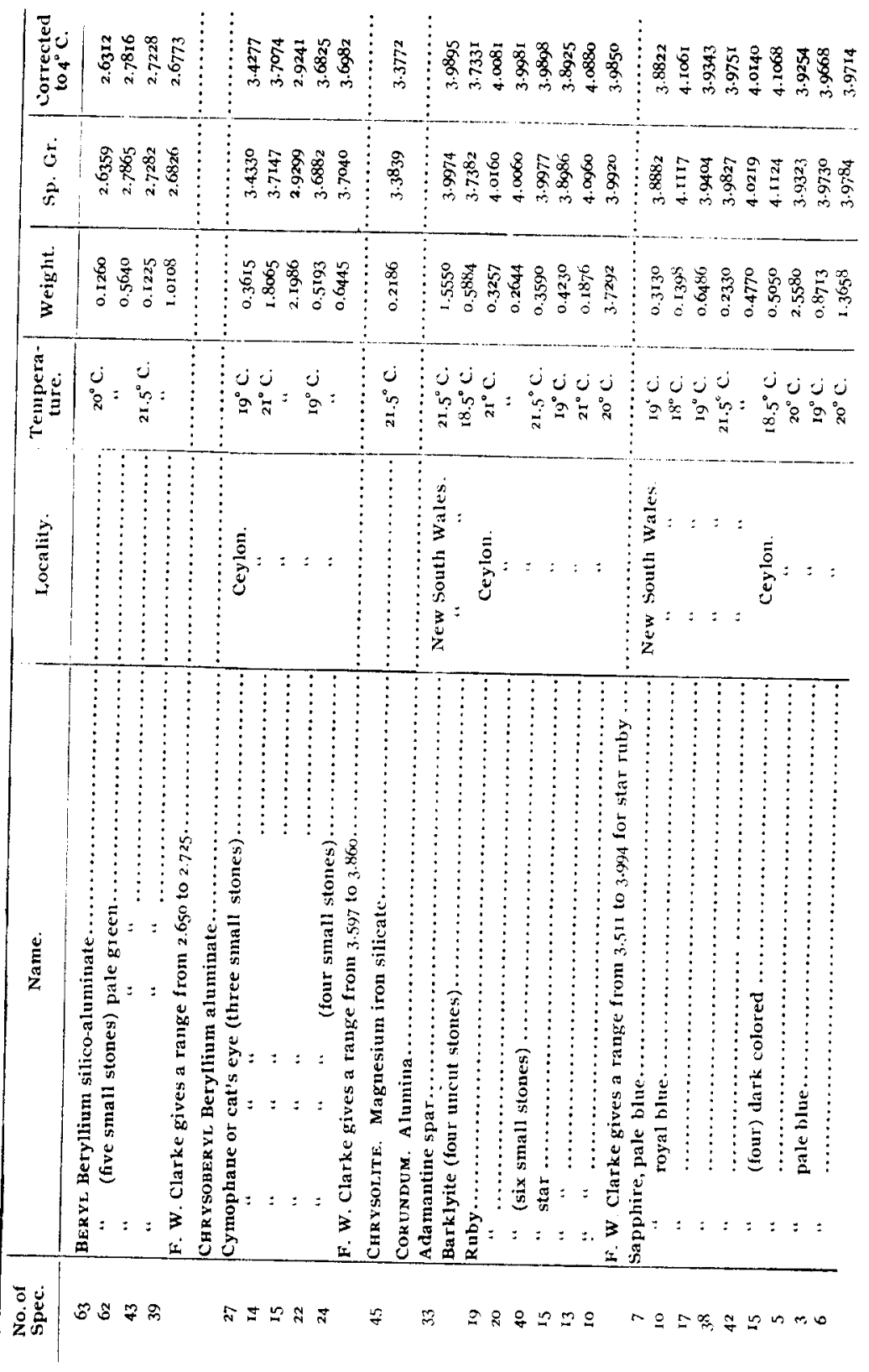




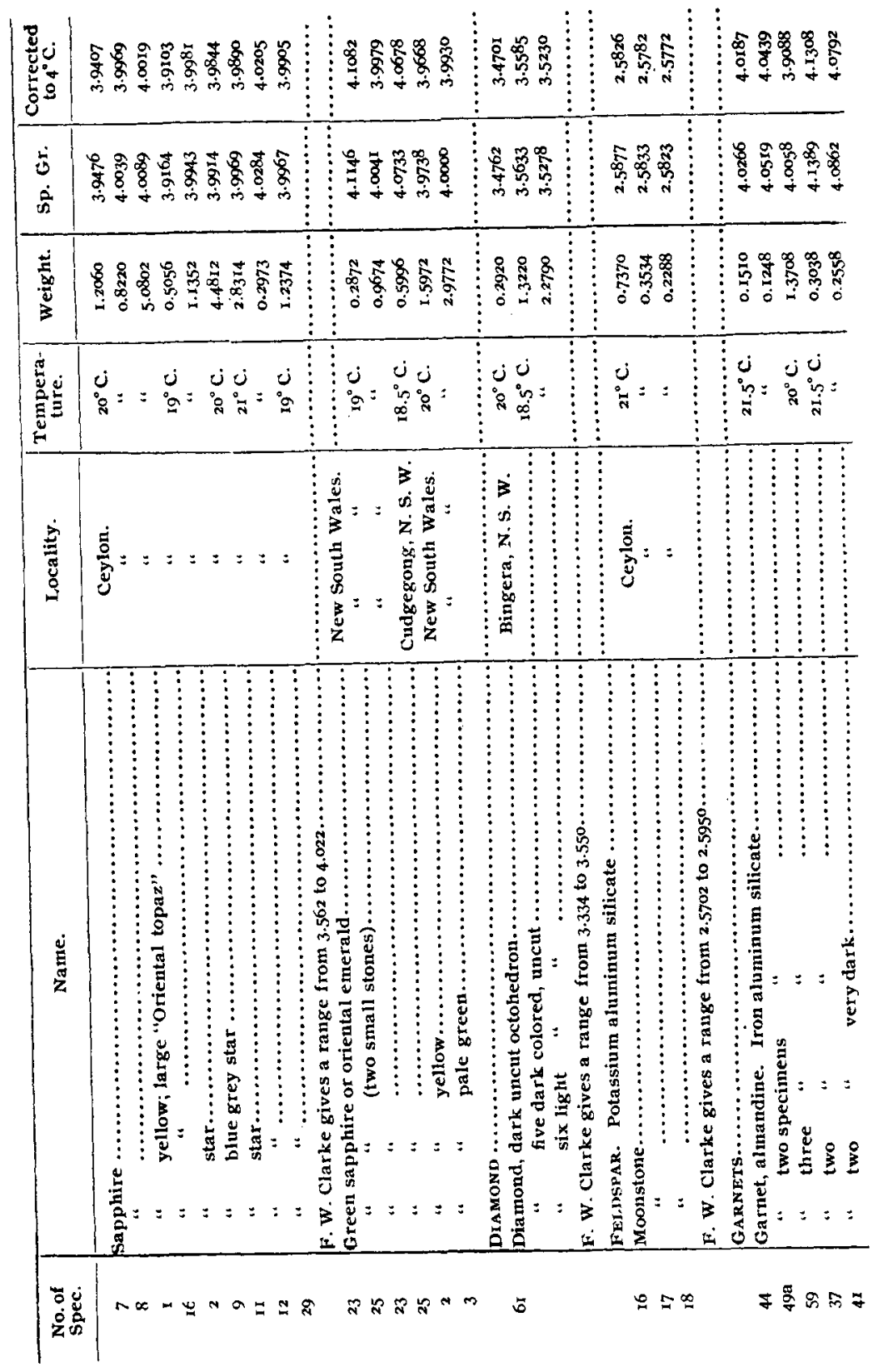




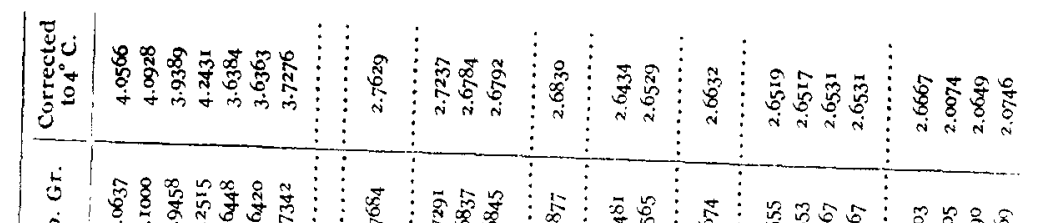

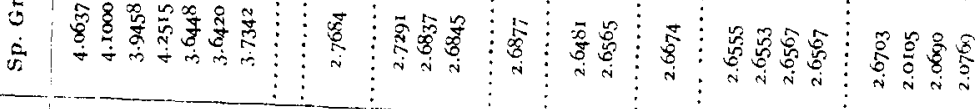

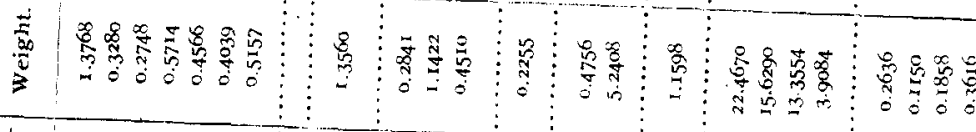

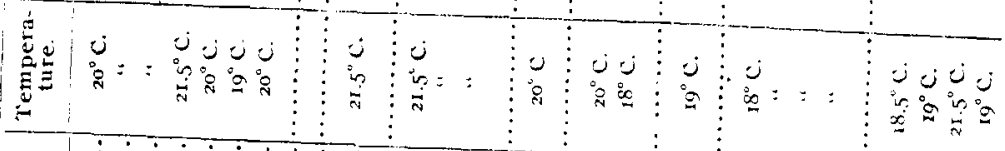

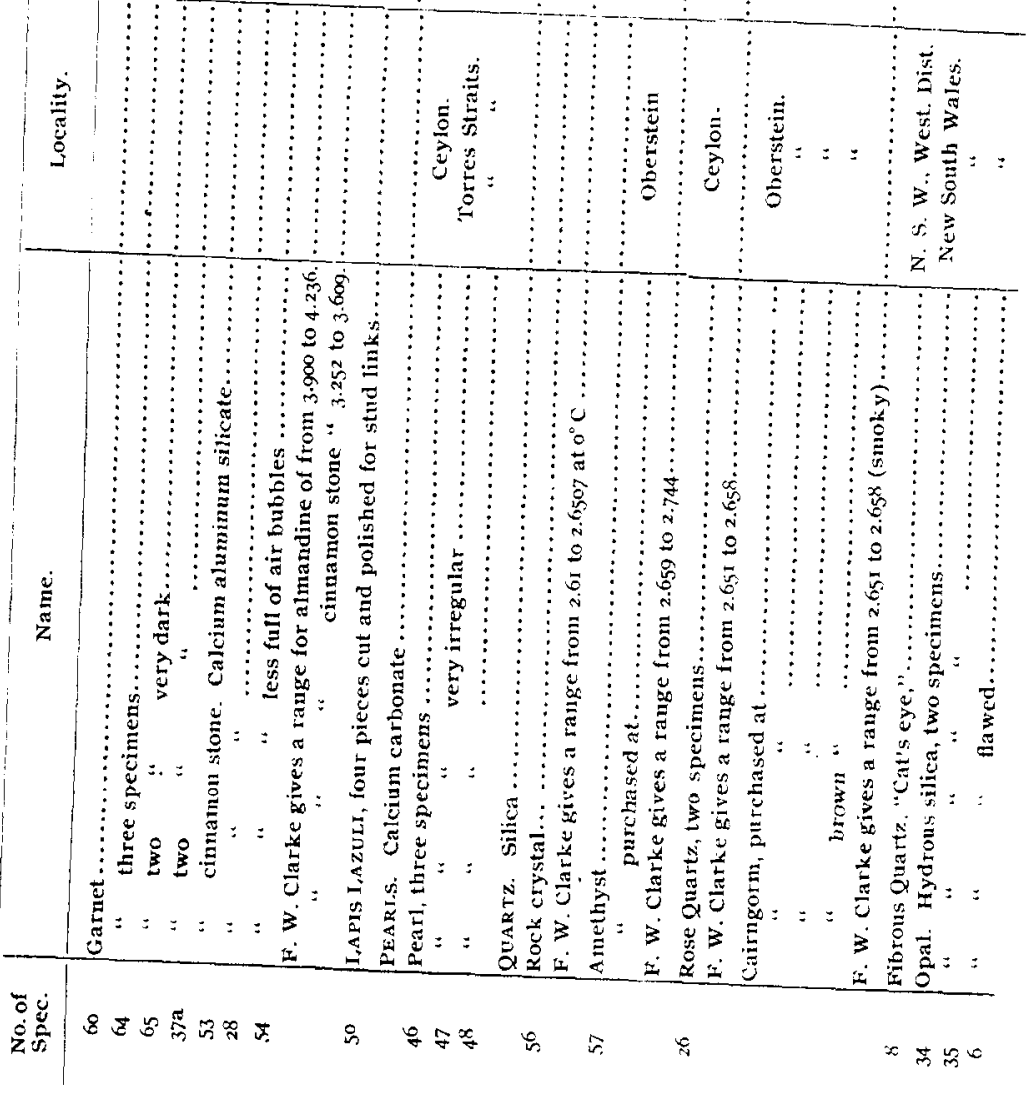




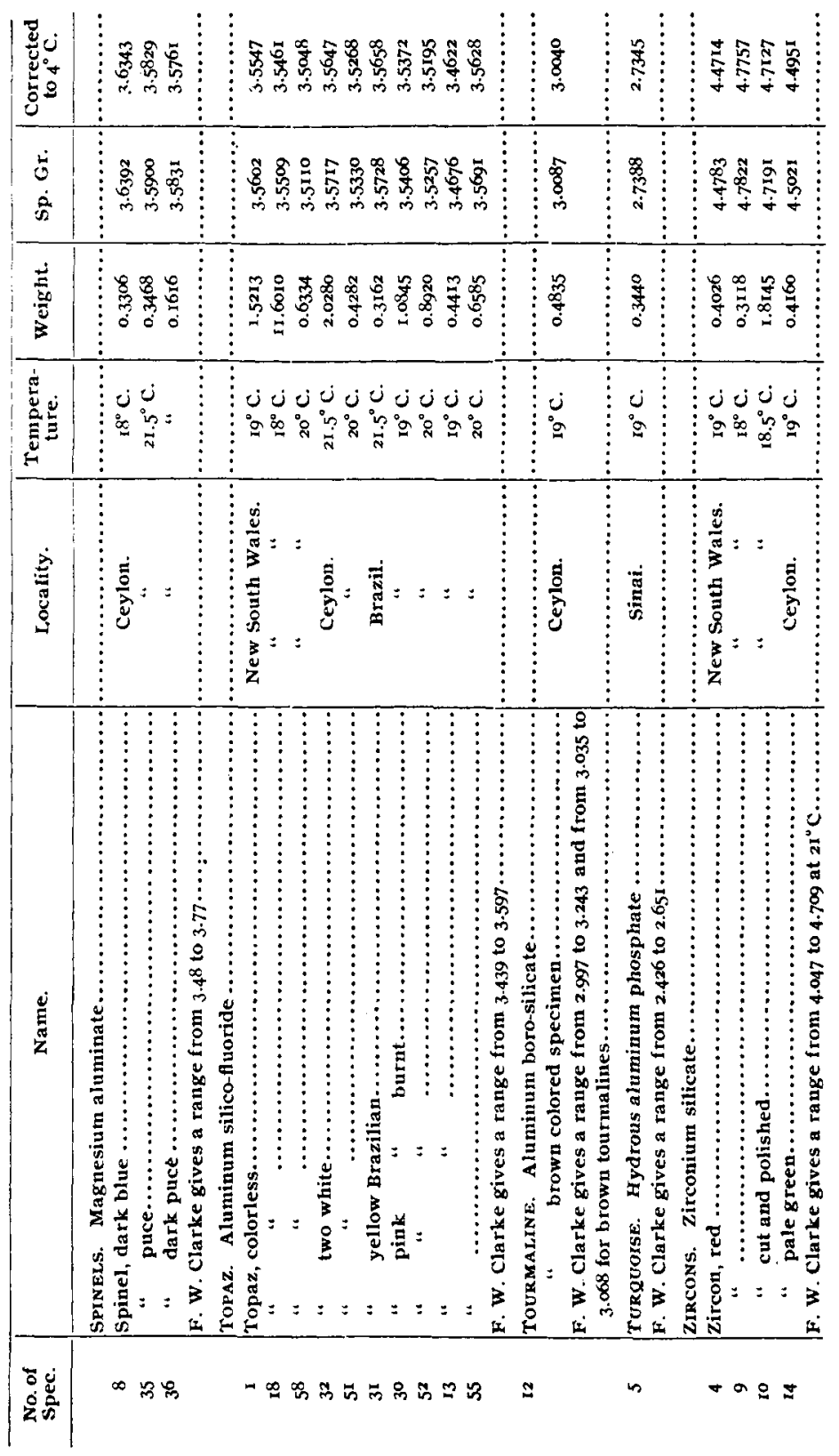

